\title{
Ammonium excretion and oxygen respiration of tropical copepods and euphausiids exposed to oxygen minimum zone conditions
}

\author{
Rainer Kiko $^{1}$, Helena Hauss ${ }^{1}$, Friedrich Buchholz ${ }^{2}$, and Frank Melzner ${ }^{1}$ \\ ${ }^{1}$ GEOMAR Helmholtz Centre for Ocean Research Kiel, Wischhofstr. 1-3, 24105 Kiel, Germany \\ ${ }^{2}$ Alfred-Wegener-Institute, Am Handelshafen 12, 27570 Bremerhaven, Germany \\ Correspondence to: Rainer Kiko (rkiko@geomar.de)
}

Received: 27 August 2015 - Published in Biogeosciences Discuss.: 28 October 2015

Revised: 8 March 2016 - Accepted: 25 March 2016 - Published: 19 April 2016

\begin{abstract}
Calanoid copepods and euphausiids are key components of marine zooplankton communities worldwide. Most euphausiids and several copepod species perform diel vertical migrations (DVMs) that contribute to the export of particulate and dissolved matter to midwater depths. In vast areas of the global ocean, and in particular in the eastern tropical Atlantic and Pacific, the daytime distribution depth of many migrating organisms corresponds to the core of the oxygen minimum zone (OMZ). At depth, the animals experience reduced temperature and oxygen partial pressure $\left(p \mathrm{O}_{2}\right)$ and an increased carbon dioxide partial pressure $\left(p \mathrm{CO}_{2}\right)$ compared to their near-surface nighttime habitat. Although it is well known that low oxygen levels can inhibit respiratory activity, the respiration response of tropical copepods and euphausiids to relevant $p \mathrm{CO}_{2}, p \mathrm{O}_{2}$, and temperature conditions remains poorly parameterized. Further, the regulation of ammonium excretion at OMZ conditions is generally not well understood. It was recently estimated that DVM-mediated ammonium supply could fuel bacterial anaerobic ammonium oxidation - a major loss process for fixed nitrogen in the ocean considerably. These estimates were based on the implicit assumption that hypoxia or anoxia in combination with hypercapnia (elevated $p \mathrm{CO}_{2}$ ) does not result in a down-regulation of ammonium excretion. We exposed calanoid copepods from the Eastern Tropical North Atlantic (ETNA; Undinula vulgaris and Pleuromamma abdominalis) and euphausiids from the Eastern Tropical South Pacific (ETSP; Euphausia mucronata) and the ETNA (Euphausia gibboides) to different temperatures, carbon dioxide and oxygen levels to study their survival, respiration and excretion rates at these conditions. An increase in temperature by $10^{\circ} \mathrm{C}$ led to an approximately 2 -
\end{abstract}

fold increase of the respiration and excretion rates of $U$.

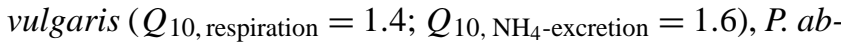
dominalis $\left(Q_{10 \text {, respiration }}=2.0 ; Q_{10, \mathrm{NH}_{4} \text {-excretion }}=2.4\right)$ and

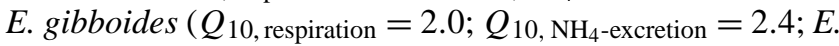
mucronata not tested). Exposure to differing carbon dioxide levels had no overall significant impact on the respiration or excretion rates. Species from the ETNA were less tolerant to low oxygen levels than E. mucronata from the ETSP, which survived exposure to anoxia at $13{ }^{\circ} \mathrm{C}$. Respiration and excretion rates were reduced upon exposure to low oxygen levels, albeit at different species-specific levels. Reduction of the excretion and respiration rates in ETNA species occurred at a $p \mathrm{O}_{2}$ of 0.6 (P. abdominalis) and $2.4 \mathrm{kPa}(U$. vulgaris and $E$. gibboides) at OMZ temperatures. Such low oxygen levels are normally not encountered by these species in the ETNA. $E$. mucronata however regularly migrates into the strongly hypoxic to anoxic core of the ETSP OMZ. Exposure to low oxygen levels led to a strong reduction of respiration and ammonium excretion in $E$. mucronata ( $p_{\text {crit respiration }}=0.6$, $p_{\text {crit NH}}$ excretion $=0.73$ ). A drastic reduction of respiratory activity was also observed by other authors for euphausiids, squat lobsters and calanoid copepods, but was not yet accounted for when calculating DVM-mediated active fluxes into the ETSP OMZ. Current estimates of DVM-mediated active export of carbon and nitrogen into the ETSP OMZ are therefore likely too high and future efforts to calculate these export rates should take the physiological responses of migratory species to $\mathrm{OMZ}$ conditions into account. 


\section{Introduction}

Many zooplankton and nekton organisms feed in the ocean's surface layer during the night and migrate to beneath the photic zone during daytime, mainly to avoid visual predation (Lampert, 1989). These so-called diel vertical migrations (DVMs) mediate the active flux of particulate and dissolved organic and inorganic matter from the surface layer to midwater depths (Steinberg et al., 2000, 2002), as the zooplankton and nekton organisms respire, excrete, defecate and die at depth. The DVM mediated active flux is an important aspect of marine biogeochemical cycles and can be as high as the passive flux via sinking particles (Putzeys, 2013). The active flux to a certain depth depends on the migrating biomass to that depth and on the respiration, excretion and defecation activity of the migrating organisms, as well as their mortality rate at the respective depth. Here we focus on the regulation of respiration and excretion rates via environmental factors. Environmental temperature (Ikeda, 2014), oxygen (Ekau et al., 2010; Seibel, 2011), and carbon dioxide levels (e.g. Rosa and Seibel, 2008; Maas et al., 2012a) modulate the activity of migrating organisms, with temperature being the best understood factor. In general, a $10^{\circ} \mathrm{C}$ temperature decrease results in an approximately 2 -fold reduction of metabolic activity (Ikeda, 2014). Likewise, hypoxia ultimately leads to reduced metabolic rates (Ekau et al., 2010; Seibel, 2011), whereas elevated $p \mathrm{CO}_{2}$ can increase or decrease metabolic rates (e.g. Rosa and Seibel, 2008; Thomsen and Melzner 2010, Kroeker et al., 2010; Maas et al., 2012a). The vertical gradients of temperature, oxygen and carbon dioxide are very pronounced at the eastern margins of tropical oceans. Here, migrating organisms encounter relatively high temperatures, high oxygen and low carbon dioxide levels at the surface, but relatively low temperatures, low oxygen and high carbon dioxide levels in the oxygen minimum zone (OMZ) at midwater depth (Karstensen et al., 2008; Paulmier et al., 2011).

OMZs in tropical oceans result from restrained mixing due to strong thermal stratification and sluggish circulation that result in a reduced oxygen supply and a comparatively high supply of particulate organic matter from the surface layer that is respired at midwater depth (Brandt et al., 2015). OMZs structure the pelagic habitat and influence the distribution and activity of marine organisms, as many organisms cannot survive at low environmental oxygen concentrations (e.g. Ekau et al., 2010). In the Eastern Tropical South Pacific (ETSP), the upper boundary of the oxycline is the single most critical factor structuring the habitat of most zooplankton organisms (Semenova et al., 1982; Escribano et al., 2009). The ETSP OMZ features severely hypoxic to anoxic conditions, with anoxia being detected at about 100 to $300 \mathrm{~m}$ depth and oxygen levels between 0 and $5 \mu \mathrm{mol} \mathrm{kg}{ }^{-1}(\sim 0$ to about $0.4 \mathrm{kPa}$ ) at about 30 to $100 \mathrm{~m}$ depth and 300 to $400 \mathrm{~m}$ depth (Thamdrup et al., 2012). In contrast, oxygen concentrations in the Eastern Tropical North Atlantic (ETNA) seldom fall below $40 \mu \mathrm{mol} \mathrm{kg}{ }^{-1}\left(\sim 3.4 \mathrm{kPa}\right.$ at $12^{\circ} \mathrm{C}$, Karstensen et al., 2008), but transient severely hypoxic to anoxic conditions have been observed in mesoscale eddies (Karstensen et al., 2015). OMZs have expanded in the recent past and a further expansion, mainly due to global warming, is expected (Stramma et al., 2008; Keeling et al., 2010). An expansion of OMZs will have far-reaching consequences for marine tropical ecosystems. For example it results in the compression of the habitat of billfishes (Stramma et al., 2012), but also in the extension of areas where fixed nitrogen is lost from the ocean (Kalvelage et al., 2011).

Many organisms have developed special adaptations like an enhanced oxygen uptake capacity to thrive at particularly low oxygen levels of less than $5 \mathrm{kPa}\left(\sim 40 \mu \mathrm{mol} \mathrm{kg}{ }^{-1}\right)$ oxygen (Childress and Seibel, 1998; Seibel, 2011). The abundance and biomass of zooplankton and nekton permanently inhabiting extreme OMZs is rather low (e.g. Wishner et al., 1998; Auel and Verheye, 2007; Escribano et al., 2009), but the migrating zooplankton and nekton biomass can be very high even in these regions. Most zooplankton and nekton organisms can regulate their oxygen uptake rate over a wide range of oxygen concentrations, but this regulatory ability breaks down at a certain critical oxygen concentration. The point at which the aerobic metabolism can no longer be maintained independent of the environmental oxygen partial pressure $\left(p \mathrm{O}_{2}\right)$ is called the critical oxygen partial pressure $p_{\text {crit }}$ (e.g. Seibel, 2011). The $p_{\text {crit }}$ is species specific and varies with habitat oxygen concentrations (e.g. Childress and Seibel, 1998; Richards, 2011) and temperature (Deutsch et al., 2015). Many species inhabiting the OMZ have evolved significantly lower $p_{\text {crit }}$ values than non-OMZ inhabiting species (Childress and Seibel, 1998) and can survive extended periods of time at oxygen levels below their $p_{\text {crit }}$ or even at anoxia (Childress, 1975; Kiko et al., 2015a). Migrations into waters with oxygen levels below the $p_{\text {crit }}$ should result in a metabolic suppression that reduces the amount of oxygen respired and carbon dioxide excreted. This reduction needs to be taken into account when calculating the active flux of respiratory carbon into the OMZ and when estimating the biological oxygen consumption within the OMZ.

The impact of hypoxia on other metabolic processes is not described as well as that on respiration. Its impact on the excretion of nitrogenous compounds is of particular interest, as pelagic primary productivity is primarily dependent on dissolved inorganic nitrogen (e.g. Hauss et al., 2012; Meyer et al., 2016). The active removal of fixed nitrogen from the euphotic zone to midwater depths is therefore an important aspect of DVMs (Steinberg et al., 2002). Furthermore, the release of ammonium in the OMZ by diel vertical migrators could possibly fuel bacterial anaerobic ammonium oxidation (anammox) - a process that removes fixed nitrogen from the ocean (Bianchi et al., 2014). Several studies have found a reduction in ammonium excretion in response to long-term (days to weeks) exposure to hypoxic and anoxic conditions for benthic and pelagic crustaceans (e.g.; Hagerman et al., 1990; Hagerman and Szaniawska, 1994; Rosas et al., 1999). 
Cass and Daly (2014) on the other hand found both enhanced and reduced rates of nitrogen excretion in response to shortterm (few hours) exposure to mild hypoxia (initial $\mathrm{O}_{2}$ concentration 36 to $78 \mu \mathrm{mol} \mathrm{O}_{2} \mathrm{~kg}^{-1}$; initial $p \mathrm{O}_{2} 2.7$ to $6 \mathrm{kPa}$ ) in different calanoid copepod species and report that excretion rates at severe hypoxia (initial $\mathrm{O}_{2}$ concentration 4 to $17 \mu \mathrm{mol} \mathrm{O} \mathrm{kg}^{-1}$; initial $p \mathrm{O}_{2} 0.3$ to $1.3 \mathrm{kPa}$ ) were too low to be measured. Svetlichny et al. (1998) showed for the Black Sea calanoid copepod Calanus euxinus that short-term exposure to mild hypoxia $\left(26 \mu \mathrm{mol} \mathrm{O} \mathrm{kg}^{-1} ; 1.9 \mathrm{kPa}\right)$ did not affect the ammonium excretion rate, whereas it resulted in a down-regulation of respiration. Maas et al. (2012b) found no reduction of ammonium excretion in three thecosomate pteropod species when animals were exposed to initial oxygen concentrations of $31.5 \pm 8 \mu \mathrm{mol} \mathrm{O}_{2} \mathrm{~kg}^{-1}(2.5 \pm 0.6 \mathrm{kPa})$. Kiko et al. (2015a) observed a very strong down-regulation of ammonium excretion in the squat lobster Pleuroncodes monodon upon exposure to anoxia and calculated a $p_{\text {crit }}$ for ammonium excretion of $0.5 \mathrm{kPa}\left(6.1 \mu \mathrm{mol} \mathrm{O} \mathrm{kg}^{-1}\right.$ at $\left.13{ }^{\circ} \mathrm{C}\right)$. In general, it still remains unclear how nitrogen excretion is regulated in response to low environmental oxygen concentrations in diel vertical migrators.

It is also not clear how the increase in $p \mathrm{CO}_{2}$ that coincides with a decrease in $p \mathrm{O}_{2}$ impacts the metabolic activity of zooplankton and nekton organisms and if interactive effects exist. Previous studies to analyse the impact of $\mathrm{OMZ}$ conditions on zooplankton metabolic activity often let the animals respire the oxygen in the test bottle (e.g. Childress, 1975; Donnelly and Torres, 1988), which would result in elevated $p \mathrm{CO}_{2}$ levels consistent with the rise in $p \mathrm{CO}_{2}$ levels in the OMZ. However, this approach could also lead to the build-up of potentially harmful amounts of metabolic endproducts. In other studies, pure nitrogen or nitrogen and oxygen mixes were used to adjust oxygen levels (e.g. Svetlichny et al., 1998; Trübenbach et al., 2013; Cass and Daly, 2014). The latter approach leads to the removal of carbon dioxide from the incubation water and therefore to a $p \mathrm{CO}_{2}$ reduction and a $\mathrm{pH}$ increase, non-representative of $\mathrm{OMZ}$ conditions (Melzner et al., 2013). In other studies, the $p \mathrm{CO}_{2}$ was adjusted to $\mathrm{OMZ}$-conditions, but not the $\mathrm{pO}_{2}$ (e.g. Maas et al., 2012a), or both $p \mathrm{O}_{2}$ and $p \mathrm{CO}_{2}$ were adjusted, but interactive effects were not tested (Kiko et al., 2015a). It is therefore necessary to develop procedures to test metabolic activity at realistic $p \mathrm{O}_{2}$ and $p \mathrm{CO}_{2}$ levels.

We here established a method to mimic the OMZ conditions (temperature, $p \mathrm{O}_{2}$ and $p \mathrm{CO}_{2}$ ) of the ETNA and ETSP using premixed $\mathrm{N}_{2} / \mathrm{O}_{2} / \mathrm{CO}_{2}$ gas mixes and tested the hypothesis that metabolic activity in copepods and euphausiids is changed under these incubation conditions compared to the incubation conditions realized when only $\mathrm{N}_{2} / \mathrm{O}_{2}$ gas mixes are used. Furthermore, we tested the hypothesis that exposure to $\mathrm{OMZ}$ conditions not only reduces the amount of oxygen respired, but also the amount of ammonium excreted. To test these hypotheses, we measured respiration and ammonium excretion rates of migrating and non-migrating copepods from the ETNA (Pleuromamma abdominalis and Undinula vulgaris, respectively) and krill species from the ETSP OMZ (Euphausia mucronata) and the ETNA OMZ (Euphausia gibboides) at different oxygen levels, carbon dioxide levels and temperatures to characterize their metabolic response. Calanoid copepods from the Pleuromamma genus are ubiquitous members of the migrating zooplankton community of the tropical Atlantic (Steinberg et al., 2000; Auel and Verheye, 2007), whereas Undinula vulgaris is a ubiquitous non-migrating epipelagic calanoid copepod of the tropical oceans (Chahsarvar-Archard and Razouls, 1982; Razouls et al., 2015). Euphausia gibboides is found regularly at low latitudes in the Atlantic and Pacific (Siegel, 2015), and E. mucronata is the dominant euphausiid in the ETSP (Antezana, 2009, 2010). Both euphausiid species conduct diel vertical migrations into the OMZ. Our work should help to better parameterize ammonium excretion and respiration rates of crustacean zooplankton and nekton in OMZ regions and aims to provide a base for revising model formulations of DVMmediated export in $\mathrm{OMZ}$ regions.

\section{Material and methods}

\subsection{Animal collection and maintenance}

Sampling was conducted during RV Maria S. Merian cruise MSM22 (ETNA; 24 October to 23 November 2012) and RV Meteor cruises M93 (ETSP; 6 February to 4 March 2013) and M97 (ETNA; 25 May to 28 June 2013; Fig. 1). Zooplankton was collected using a Hydrobios Multinet Midi $\left(0.25 \mathrm{~m}^{2}\right.$ mouth opening, $200 \mu \mathrm{m}$ mesh size, 5 nets), a Hydrobios Multinet Maxi $\left(0.5 \mathrm{~m}^{2}\right.$ mouth opening, $330 \mu \mathrm{m}$ mesh size, 9 nets $)$, a WP-2 net $\left(0.26 \mathrm{~m}^{2}\right.$ mouth opening, $200 \mu \mathrm{m}$ mesh size), a MOCNESS ( $1 \mathrm{~m}^{2}$ mouth opening, $2 \mathrm{~mm}$ mesh size) or a CalCOFI-Net $\left(0.78 \mathrm{~m}^{2}\right.$ mouth opening, $500 \mu \mathrm{m}$ mesh size). All specimens used for experiments were caught in the upper $400 \mathrm{~m}$ of the water column and only animals appearing unharmed and fit were used for experiments. Specimens were sorted, identified and transferred into aquaria with filtered, well-oxygenated seawater immediately after the catch and maintained for 1 to $13 \mathrm{~h}$ prior to physiological experiments at the respective experimental temperature. Only adult euphausiids and adult female copepods were used for the experiments. OMZ temperatures during MSM22 and M97 ranged from 5.5 to $13.6^{\circ} \mathrm{C}$ at 300 to $600 \mathrm{~m}$ depth and from 13 to $29^{\circ} \mathrm{C}$ in the upper $100 \mathrm{~m}$. Temperature at 200 to $300 \mathrm{~m}$ depth during M93 ranged from 10.2 to $13.3^{\circ} \mathrm{C}$. Maintenance and physiological experiments were therefore conducted in darkness in temperature-controlled incubators at 11,13 or $23^{\circ} \mathrm{C}\left( \pm 1^{\circ}\right)$. Animals were not fed before or during experiments.

Stomach fullness and colouration of the mid gut gland were routinely categorized in E. gibboides. Possible scores of the mid gut gland colouration were $0-5$, indicating trans- 

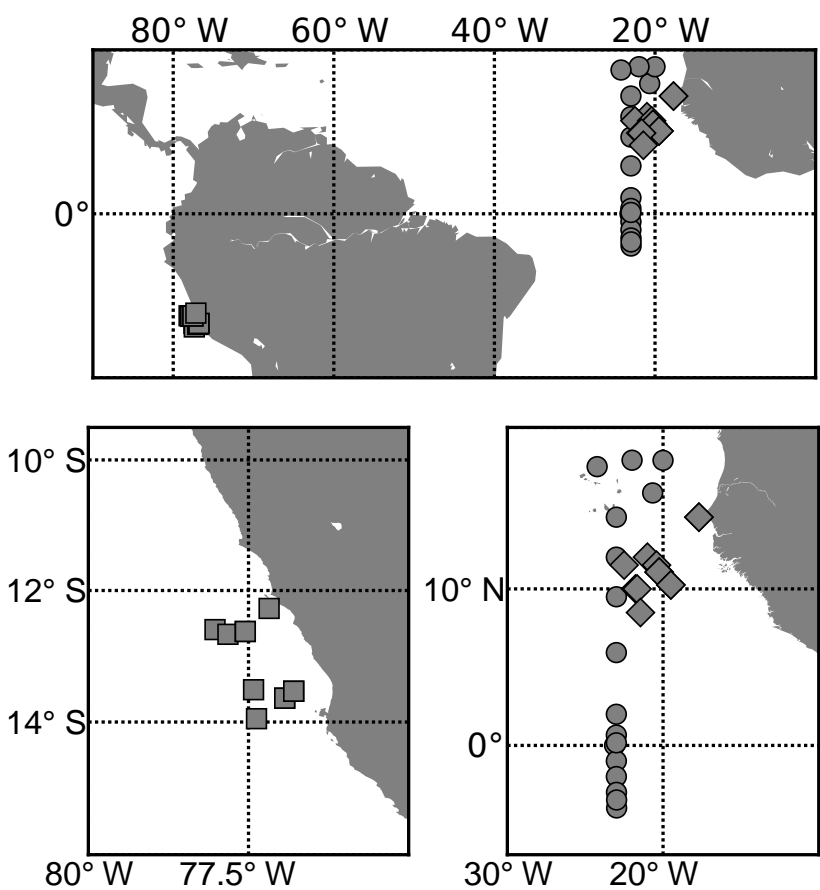

Figure 1. Sampling locations of specimens for respiration and excretion measurements. Circles: Pleuromamma abdominalis and Undinula vulgaris during cruise MSM22 (October/November 2012); Squares: Euphausia mucronata during cruise M93 (February 2013); Diamonds: Euphausia gibboides during cruise M97 (May 2013).

parent through green to dark brown colouration (Morris et al., 1983).

\subsection{Incubation conditions}

Respiration and ammonium excretion rate measurements (both in $\mu \mathrm{mol} \mathrm{h}^{-1} \mathrm{gDW}^{-1}$ ) at varying oxygen concentrations were conducted simultaneously in 12 to $60 \mathrm{~mL}$ gas-tight glass bottles. These were equipped with oxygen microsensors ( $\varnothing 3 \mathrm{~mm}$, PreSens Precision Sensing GmbH, Regensburg, Germany) attached to the inner wall of the bottles to monitor oxygen concentrations non-invasively. Read-out of oxygen concentrations was conducted using multi-channel fiber optic oxygen transmitters (Oxy-4 and Oxy-10 mini, PreSens Precision Sensing GmbH, Regensburg, Germany) that were connected via optical fibers to the outside of the bottles directly above the oxygen microsensor spots. Calibration of the oxygen microsensors was conducted at the beginning of each cruise or when a different incubation temperature was set with a $\mathrm{Na}_{2} \mathrm{SO}_{3}$-solution $(0 \%$ oxygen) and aerated seawater (100\% air saturation) at the respective measurement temperature. Oxygen concentration was calculated from air saturation according to the PreSens manual. All other oxygen unit conversions were conducted using the R-package AquaEnv (Hofmann et al., 2010) and R scripts obtained from
Andreas F. Hofmann. Measurements were started at preadjusted oxygen and carbon dioxide levels. For this, seawater stocks with adjusted $p \mathrm{O}_{2}$ and $p \mathrm{CO}_{2}$ were prepared by equilibrating 3 to $4 \mathrm{~L}$ of filtered $(0.2 \mu \mathrm{m}$ Whatman GFF filter) and UV-sterilized (Aqua Cristal UV C 5 Watt, JBL GmbH and Co. KG, Neuhofen, Germany) water with premixed gases (certified gas mixtures from Air Liquide) for $4 \mathrm{~h}$ at the respective experimental temperature. $p \mathrm{CO}_{2}$ levels were chosen to mimic the environmental $p \mathrm{CO}_{2}$ in the ETSP OMZ or the ETNA OMZ. $p \mathrm{CO}_{2}$ levels for the respective area were calculated from data published by the World Ocean Circulation Experiment (WOCE 2002; ETSP: data from the upper $150 \mathrm{~m}$ between 14.74 to $16.38^{\circ} \mathrm{S}$ and 75.25 to $76.93^{\circ} \mathrm{W}$; ETNA: data from the upper $400 \mathrm{~m}$ between $4.5^{\circ} \mathrm{S}$ to $11^{\circ} \mathrm{N}$ and 7 to $26^{\circ} \mathrm{W}$ ) using CO2sys_v2.1 (Pierrot et al., 2006). Furthermore, gas mixes with different levels of oxygen, but without $\mathrm{CO}_{2}$ were used to test the effects of this experimental manipulation. The detailed composition of the premixed gases used is described in Table 1 . Antibiotics $\left(25 \mathrm{mg} \mathrm{L}^{-1}\right.$ ampicillin and $25 \mathrm{mg} \mathrm{L}^{-1}$ streptomycin) were added to the stocks after equilibration to inhibit microbial activity.

The salinity and $\mathrm{pH}$ of the prepared water were measured immediately on board with a handheld multiparameter metre Multi 350i equipped with a Sentix $41 \mathrm{pH}$ and a ConOx conductivity probe (WTW). Calibration of the $\mathrm{pH}$-probe was conducted daily prior to the measurements using 7.000 and $10.012 \mathrm{pH}$ IUPAC standard buffers (Radiometer analytical) and the conductivity probe was calibrated at the beginning of each cruise using $0.01 \mathrm{~mol} \mathrm{~L}^{-1} \mathrm{KCl} .250 \mathrm{~mL}$ of the prepared water was collected in gas-tight glass bottles and fixed with $100 \mu \mathrm{L}$ saturated mercury chloride solution for later measurements of total alkalinity $\left(A_{\mathrm{T}}\right)$ and dissolved inorganic carbon $\left(C_{\mathrm{T}}\right)$ in the home laboratory. $C_{\mathrm{T}}$ was measured using an AIRICA system (Marianda, Kiel, Germany) via a LI-COR 7000 infrared $\mathrm{CO}_{2} / \mathrm{H}_{2} \mathrm{O}$ analyser. $A_{\mathrm{T}}$ was measured in duplicates via potentiometric titration with an automated titrator (Titroline 7000, SI Analytics, Germany) using $50 \mathrm{~mL}$ of sample and $0.05 \mathrm{M} \mathrm{HCl}$. $C_{\mathrm{T}}$ was measured for samples from cruise MSM22, whereas $A_{\mathrm{T}}$ was measured for samples from cruises M93 and M97, due to a breakdown of the $C_{\mathrm{T}}$ measurement system. $A_{\mathrm{T}}$ and $C_{\mathrm{T}}$ were measured against certified reference material provided by Andrew Dickson of Scripps Institution of Oceanography (http://andrew.ucsd.edu/co2qc/). The $p \mathrm{CO}_{2}$ established in the different incubation trials was calculated with CO2sys_v2.1, using experimental temperature, water salinity, $\mathrm{pH}_{\mathrm{NBS}}$ and $C_{\mathrm{T}}$ or $A_{\mathrm{T}}$ as input.

\subsection{Excretion and respiration measurement}

Experimental runs to simultaneously measure the ammonium excretion and respiration rates were conducted with 11 to 15 trial incubations ( 1 or 2 animals per incubation bottle and three different treatment levels) and three animal-free control incubations (experimental treatment) per run. During each run, experimental treatments comprised $100 \%$ air 
Table 1. Volumetric composition of used premixed gases.

\begin{tabular}{llrrr}
\hline & & $50 \%$ air sat. & $33 \%$ air sat. & $10 \%$ air sat. \\
\hline \multirow{3}{*}{ ETNA CO 2 -plus } & Nitrogen & 89.58 & 93.02 & 97.85 \\
& Oxygen & 10.36 & 6.91 & 2.07 \\
& Carbon dioxide & 0.06 & 0.07 & 0.08 \\
\hline \multirow{2}{*}{ ETSP CO $_{2}$-plus } & Nitrogen & 89.53 & 92.96 & 97.77 \\
& Oxygen & 10.36 & 6.91 & 2.07 \\
& Carbon dioxide & 0.11 & 0.13 & 0.16 \\
\hline \multirow{2}{*}{$\mathrm{CO}_{2}$-minus } & Nitrogen & 89.64 & 93.09 & 97.93 \\
& Oxygen & 10.36 & 6.91 & 2.07 \\
& Carbon dioxide & 0.00 & 0.00 & 0.00 \\
\hline
\end{tabular}

saturation as well as one reduced air saturation level with and without $\mathrm{CO}_{2}$. A typical run for example comprised three replicates plus one animal-free control at $100 \%$ air saturation, four replicates plus one animal-free control at $50 \%$ air saturation plus $\mathrm{CO}_{2}$ and four replicates plus one animal-free control at $50 \%$ air saturation minus $\mathrm{CO}_{2}$. To start the incubations, the incubation bottles were filled with the respective prepared water and the animals were added immediately. This handling took a maximum of $5 \mathrm{~min}$ for each animal and about 30 min for all replicates. Subsequently, the respective incubation bottle was immediately transferred to the incubator. Oxygen concentrations in the incubation bottles were recorded every $5 \mathrm{~min}$ using the fiber-optic microsensor system and the recording of data for the determination of respiration rates was started immediately after all animals were transferred. Respiration rates were calculated from the slope of oxygen decrease over selected time intervals. Chosen time intervals were 20 to $105 \mathrm{~min}$ long. No respiration rate was calculated for the first 20 to $60 \mathrm{~min}$ after animal transfer to avoid the impact of enhanced activity of the animal or changes in the bottle water temperature during initial handling on the respiration rates and oxygen readings. Respiration rates were obtained over a maximum incubation time of $16 \mathrm{~h}$ and slopes were linear at normoxia to mild hypoxia. Respiration rates in animal-free control bottles were used to correct for microbial activity. These rates were $<2 \%$ of animal respiration rates at normoxia.

Animals were incubated for 2 to $10 \mathrm{~h}$ for the measurement of ammonium excretion rates. Ammonium concentration was determined fluorometrically (Holmes et al., 1999). Ammonium excretion was calculated as the concentration difference between incubation and animal-free control bottles. Some specimens died during the respiration and excretion rate measurements, as indicated by a cessation of respiration. No excretion rate measurements were conducted in this case, but the oxygen level at which the animal died was noted.

Euphausia mucronata survived exposure to anoxia, enabling the measurement of ammonium excretion rates under severely hypoxic to anoxic conditions. These measure- ments were started after $2-5 \mathrm{~h}$ when animals had respired all oxygen from the incubation bottles. Thereafter, a $1 \mathrm{~mL}$ water sample was taken from the $12-13 \mathrm{~mL}$ bottles used to determine the ammonium concentration at the onset of the trial. The withdrawn water was replaced with $0 \%$ oxygen water prepared using pure nitrogen gas. Oxygen levels slightly increased during this procedure, but never rose above $\sim 3 \%$ air saturation. This small amount of oxygen was in most cases respired after about $30 \mathrm{~min}$, but in some cases anoxia was not reached until the end of the trial. After an incubation period of $2.5 \mathrm{~h}$ at severe hypoxia to anoxia, a second sample for the ammonium concentration measurement was taken. The ammonium excretion rate was calculated as the difference between the first and second measurement and the oxygen concentration was calculated as the mean of the initial and end oxygen concentrations. All individuals used in the described experiments were subsequently frozen at $-80^{\circ} \mathrm{C}$, dried at $50^{\circ} \mathrm{C}$ for $72 \mathrm{~h}$ and weighed to determine their dry weight. Oxygen consumption and ammonium excretion rates $\left(R, \mu \mathrm{molh}^{-1} \mathrm{gDW}^{-1}\right)$ were standardized to an average dry weight (DW in $\mathrm{mg}$ ) of $0.1 \mathrm{~g}$ applying a scaling coefficient $b$ of -0.25 (Moloney and Field, 1989) as

$R_{\text {std }}=R \times\left(\frac{0.1}{\text { weight }}\right)^{-0.25}$.

The rates presented should be considered routine metabolic rates, as activity was not monitored and animals were not fed (Prosser, 1961).

\subsection{Statistical analysis}

General linear models (GLM) with $p \mathrm{O}_{2}$ as a continuous variable and $p \mathrm{CO}_{2}$ (two levels) and temperature (for all except E. mucronata, two levels) as a categorical predictor were used on log-transformed respiration and excretion rate data for each species separately to explore the overall effect of experimental conditions on the metabolic response.

Pairwise t-tests were employed to compare the respiration and excretion rates of the two $p \mathrm{CO}_{2}$-treatments maintained under similar temperature and $p \mathrm{O}_{2}$ conditions. For 
these tests, the mean respiration rate obtained at a given experimental condition (starting $\mathrm{pO}_{2}$ value and experimental temperature) for a replicate was determined. E.g. if an experimental run with an animal was started at $50 \%$ air saturation, stopped at $20 \%$ air saturation and lasted $8 \mathrm{~h}$, four determinations of the respiration rate were available for this replicate and the mean of these respiration rates was determined. To analyse the effects of different oxygen levels on the respiratory activity, the four determinations of the respiration rates obtained at different oxygen levels were used separately for subsequent analysis.

Where possible, metabolic rates were modelled as a function of $\mathrm{pO}_{2}$ using nonlinear regressions with the python module lmfit. If hypoxia was found to have lethal effects at a given temperature, the metabolic data were transformed prior to fitting the power function by subtracting the lowest observed lethal $p \mathrm{O}_{2}$ from the abscissa data. A power function with a y-intercept of zero

$R_{\text {std, } \mathrm{O}_{2}}=a \times p \mathrm{O}_{2}^{b}$

was fitted to the standardized (according to Eq. 1) and transformed respiration rate data as the respiration rate at $0 \mathrm{kPa}$ oxygen or that of dead individuals is zero by definition. A power function with $y$ intercept

$R_{\mathrm{std}, \mathrm{NH}_{4}}=a \times p \mathrm{O}_{2}{ }^{b}+c$

was fitted to the standardized and transformed ammonium excretion rate data.

To calculate the $p_{\text {crit }}$, the standardized and transformed respiration or excretion rates were normalized by dividing each respiration or excretion rate by the highest observed respiration or excretion rate, respectively. Power functions as described above were fitted to these standardized, transformed and normalized rates. The respiration or excretion $p_{\text {crit }}$ was then calculated according to Marshall et al. (2013) as

$p_{\text {crit }}=\left(\frac{0.065}{a \times b}\right)^{\left(\frac{1}{1-b}\right)}$,

where $\mathrm{a}$ and $\mathrm{b}$ are the respective factors obtained from fitting Eq. (2) or (3) to the standardized and normalized rates.

The fitted functions and the calculated $p_{\text {crit }}$ were backtransformed to the original scaling of the abscissa.

\section{Results}

\subsection{Impact of $p \mathrm{CO}_{2}$-levels on respiration and excretion}

We prepared incubation water using both $\mathrm{O}_{2} / \mathrm{N}_{2}$-mixes ( $\mathrm{CO}_{2}$-minus) and $\mathrm{O}_{2} / \mathrm{N}_{2} / \mathrm{CO}_{2}$-mixes $\left(\mathrm{CO}_{2}\right.$-plus $)$ to test if differences in $\mathrm{pH}$ and $p \mathrm{CO}_{2}$ in the incubation water lead to significant differences in the metabolic activity of copepods

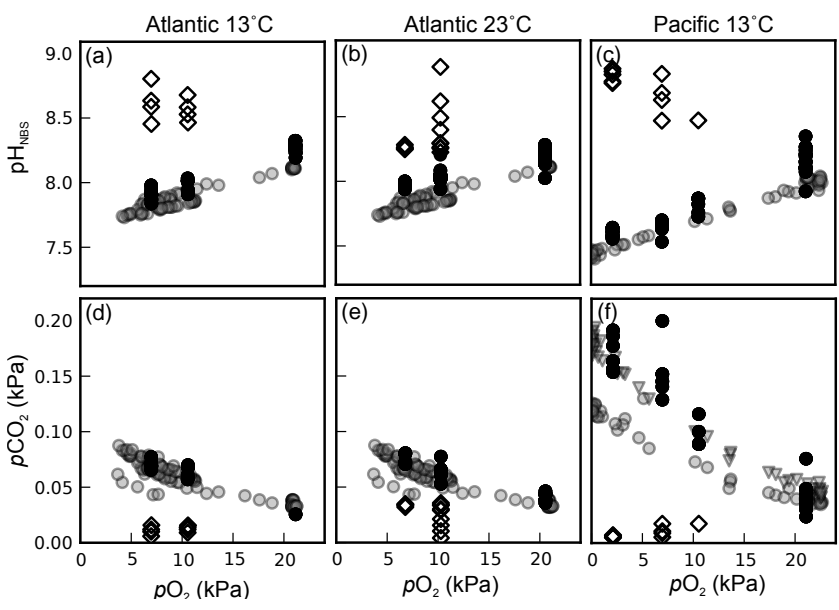

Figure 2. $\mathrm{pH}_{\mathrm{NBS}}$ and $p \mathrm{CO}_{2}$ in incubation water (black symbols), compared to environmental levels (grey symbols) for the ETNA OMZ and the ETSP OMZ. Black circles: $\mathrm{CO}_{2}$-plus treatment. Open diamonds: $\mathrm{CO}_{2}$-minus treatment. Grey circles: environmental $\mathrm{pH}$ or $p \mathrm{CO}_{2}$ data, $p \mathrm{CO}_{2}$ calculated from $A_{\mathrm{T}}$ and $C_{\mathrm{T}}$. Grey triangles in $F$ : $p \mathrm{CO}_{2}$ calculated from $\mathrm{pH}$ and $A_{\mathrm{T}}$.

and euphausiids from the ETNA and ETSP. $\mathrm{O}_{2} / \mathrm{N}_{2} / \mathrm{CO}_{2-}$ mixes representative of the respective regions were used. The use of $\mathrm{O}_{2} / \mathrm{N}_{2}$-mixes led to an artificial reduction of the $p \mathrm{CO}_{2}$ and an artificial increase in $\mathrm{pH}$ compared to untreated seawater $\left(p \mathrm{O}_{2} \sim 21 \mathrm{kPa}\right.$; Fig. 2). Differences to the respective simulated OMZ conditions were even larger and increased with decreasing oxygen levels (Fig. 2). The use of $\mathrm{O}_{2} / \mathrm{N}_{2} / \mathrm{CO}_{2}$-mixes resulted in $\mathrm{pH}$ and $p \mathrm{CO}_{2}$ levels that were very close to the environmental target conditions for the ETNA OMZ, whereas $p \mathrm{CO}_{2}$ levels were slightly above those of the ETSP OMZ.

In the general linear model (GLM) with the mean $p \mathrm{O}_{2}$ as continuous and $p \mathrm{CO}_{2}$ and - if applicable - temperature as categorical predictors, applied to each species separately, no significant overall effects of the $\mathrm{CO}_{2}$-level on the respiration or excretion rates were detected $(p>0.1)$, while temperature and $p \mathrm{O}_{2}$ were significant (univariate $p<0.0001$ for respiration, $p<0.05$ for excretion, all species) predictors of metabolic activity. Respiration whole model adjusted $r^{2}$ was 0.63, 0.36, 0.41 and 0.37 for E. gibboides, E. mucronata, Pleuromamma abdominalis and Undinula vulgaris, respectively and ammonium excretion whole model adjusted $r^{2}$ was 0.30, 0.31, 0.84 and 0.77 for E. gibboides, E. mucronata, $P$. abdominalis and $U$. vulgaris, respectively.

In the pairwise comparison, respiration and ammonium excretion rates of animals incubated in $\mathrm{CO}_{2}$-plus waters were not found to be significantly different from those incubated in $\mathrm{CO}_{2}$-minus waters at most oxygen and $\mathrm{CO}_{2}$ levels analysed ( $t$ tests, $p$ value >0.05; Figs. 3 and 4). However, in Euphausia mucronata incubated at $33 \%$ air saturation at $13{ }^{\circ} \mathrm{C}$, the $\mathrm{CO}_{2}$-plus treatment resulted in a significant 1.35 -fold increase $(p<0.05)$ in respiration. No effect was observed in 

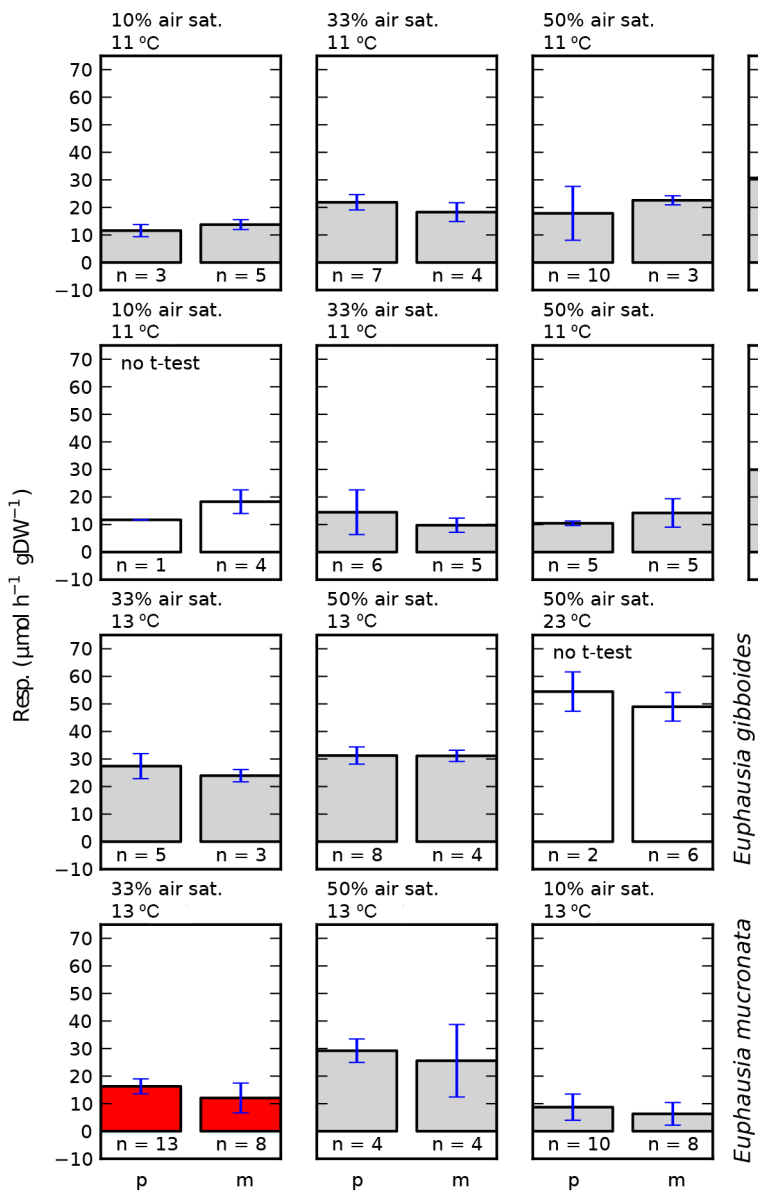

Figure 3. Weight-specific respiration rates of calanoid copepods and euphausiids at different temperatures, air saturation and $\mathrm{CO}_{2}$-levels. $p=\mathrm{CO}_{2}$-plus, $m=\mathrm{CO}_{2}$-minus. Red barplot colour indicates a statistically significant difference $(t$ test, $p<0.05)$ between $\mathrm{CO}_{2}$-plus and $\mathrm{CO}_{2}$-minus treatments. Each row contains data for only one species, with low temperatures on the left side of the row and high temperatures on the right side and air saturation increasing from left to right.

this species at $10 \%$ air saturation and no consistent effects were observed in any other species. Likewise, the $\mathrm{CO}_{2}$-plus treatment resulted in a significant 1.6-fold increase $(p<0.05)$ in ammonium excretion in P. abdominalis at $33 \%$ air saturation and $11^{\circ} \mathrm{C}$, but no effects were observed in this species at any other condition tested or in any other species. To estimate the sensitivity of our analysis we artificially increased the respiration rates at $\mathrm{CO}_{2}$-plus or $\mathrm{CO}_{2}$-minus conditions stepwise by a factor of 0.1 to determine the fold changes at which more than $50 \%$ of the tests become significant. This was the case at a 1.2-fold increase for the respiration rate tests ( 7 of 14 tests significant) and a 1.5-fold increase for the excretion rate tests ( 6 of 11 tests significant). As no consistent significant effects of our $\mathrm{CO}_{2}$-treatment were found, we combined data from $p \mathrm{CO}_{2}$-plus and $p \mathrm{CO}_{2}$-minus incubations to further characterize the effects of temperature and oxygen levels on metabolic activity.

\subsection{Temperature and oxygen-dependence of respiration and hypoxia tolerance}

Respiration rates at normoxia (trial start conditions $100 \%$ air saturation) were always significantly lower at 11 or $13^{\circ} \mathrm{C}$ than at $23^{\circ} \mathrm{C}$ in Undinula vulgaris, Pleuromamma abdominalis and Euphausia gibboides ( $t$ test, $p<0.05)$. The $Q_{10}$ temperature coefficient of respiration at normoxia $\left(p \mathrm{O}_{2}>15 \mathrm{kPa}\right.$, Temp. $=11-23^{\circ} \mathrm{C}$ ) was 1.4 for $U$. vulgaris, and 2.0 for P. abdominalis and E. gibboides (Table 3). Standardized individual respiration rates and fitted power functions are shown in the upper panels of Figs. 5 and 6. Respiratory $p_{\text {crit }}$ of $E$. gibboides and $P$. abdominalis were 2.4 (at $13^{\circ} \mathrm{C}$ ) and $0.6 \mathrm{kPa}\left(\right.$ at $11^{\circ} \mathrm{C}$ ), respectively (Figs. 5 and 6 , Table 3). As no data on respiratory activity below $1.9 \mathrm{kPa}$ were obtained for $P$. abdominalis, the $p_{\text {crit }}$ likely lies between the calculated $p_{\text {crit }}$ of 0.6 and $1.9 \mathrm{kPa}$. In the case of $E$. gibboides the respiratory $p_{\text {crit }}$ was almost identical with the mean lethal $p \mathrm{O}_{2}$ of $2.5 \mathrm{kPa}(\mathrm{SD}=1.4, n=20)$ at $13^{\circ} \mathrm{C}$. The mean lethal $p \mathrm{O}_{2}$ of $U$. vulgaris was $2.7 \mathrm{kPa}(\mathrm{SD}=0.3$, 


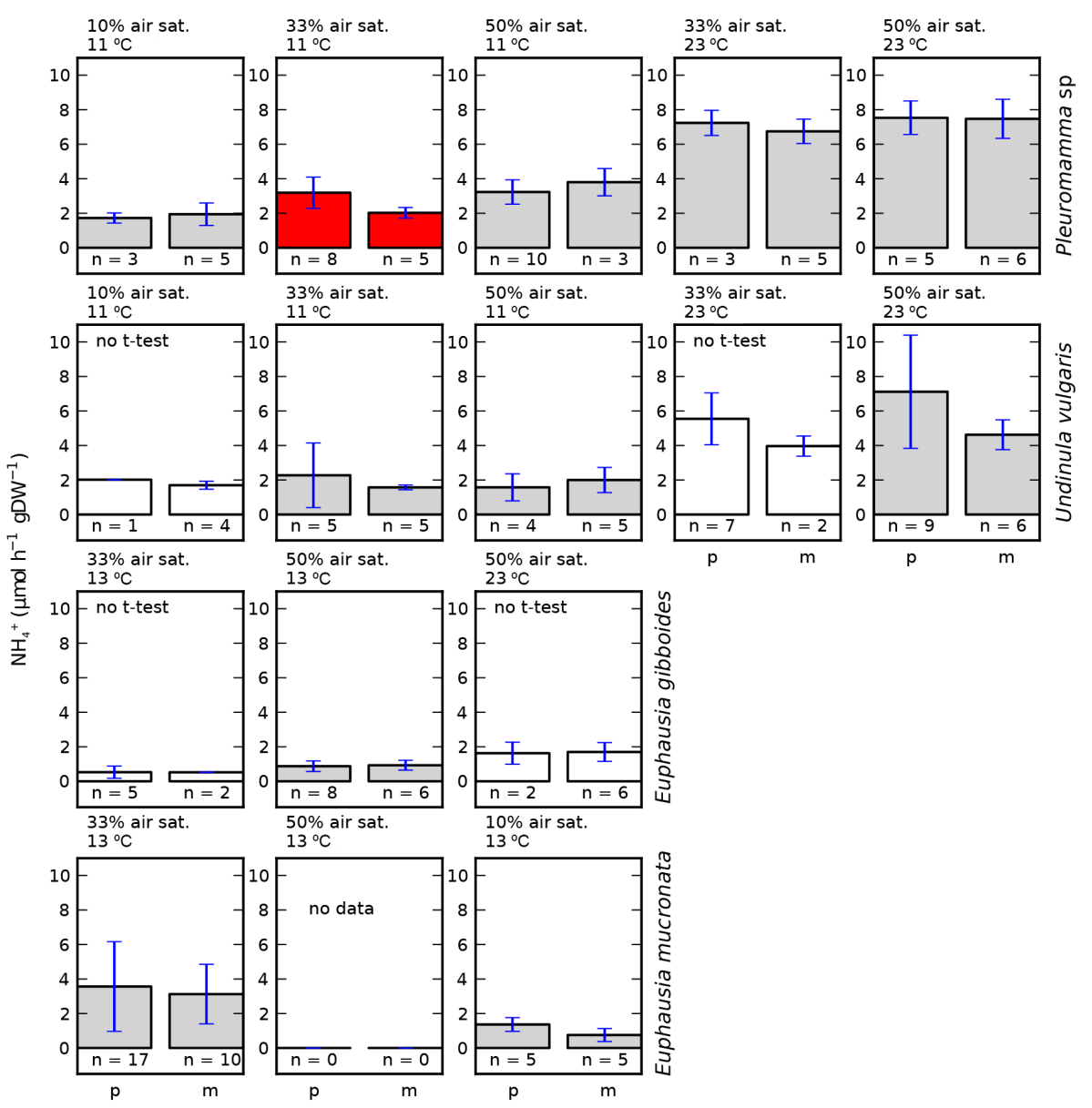

Figure 4. Weight-specific ammonium excretion rates of calanoid copepods and euphausiids at different temperatures, air saturation and $\mathrm{CO}_{2}$-levels. $p=\mathrm{CO}_{2}$-plus, $m=\mathrm{CO}_{2}$-minus. Red barplot colour indicates a statistically significant difference $(t$ test, $p<0.05)$ between $\mathrm{CO}_{2}$ plus and $\mathrm{CO}_{2}$-minus treatments. Each row contains data for only one species, with low temperatures on the left side of the row and high temperatures on the right side and air saturation increasing from left to right.

$n=6)$ at $11^{\circ} \mathrm{C}$. No mortality was observed for P. abdominalis down to $1.9 \mathrm{kPa}$ at $11^{\circ} \mathrm{C}$. E. mucronata survived several hours at anoxia at $13{ }^{\circ} \mathrm{C}$, but survival time at anoxia was not systematically determined. The respiratory $p_{\text {crit }}$ of E. mucronata was found to be $0.6 \mathrm{kPa}$ at $13{ }^{\circ} \mathrm{C}$. Data from Teal and Carey (1967) supplement our observations on the respiratory rates of E. mucronata. From their Fig. 2, an approximate $p_{\text {crit }}$ of 2 to $4 \mathrm{kPa}$ at $20^{\circ} \mathrm{C}$ can be deduced. In all species that we tested, the respiratory $p_{\text {crit }}$ was higher at $23^{\circ} \mathrm{C}$ than at 11 or $13^{\circ} \mathrm{C}$ (Table 3). At $23^{\circ} \mathrm{C}$, the mean lethal $p \mathrm{O}_{2}$ was $6.6 \mathrm{kPa}$ in $U$. vulgaris $(\mathrm{SD}=0.7, n=6), 6.3$ in P. abdominalis $(\mathrm{SD}=1.0, n=2)$ and 7.5 in E. gibboides $(\mathrm{SD}=1.9, n=20)$. Respiration rates calculated according to Ikeda (2014) for $0.1 \mathrm{~g}$ copepods or euphausiids coincided well with the standardized respiration rates observed at normoxia in all species (Figs. 5, 6).

\subsection{Ammonium excretion rates}

The $Q_{10}$ temperature coefficient of ammonium excretion at normoxia (trial start conditions $100 \%$ air saturation) was 1.6 for Undinula vulgaris, and 2.3 for both Pleuromamma $a b$ dominalis and Euphausia gibboides. It was possible to fit power functions to most ammonium excretion data (Figs. 5 and 6, Table 3) except for $U$. vulgaris at $23^{\circ} \mathrm{C}$ and for $E$. gibboides at 13 and $23^{\circ} \mathrm{C}$. For the latter species and experimental conditions students t-tests grouped by initial oxygen concentrations revealed no statistically significant changes in excretion rates with decreasing oxygen levels, compared to the excretion rates at normoxia. The ammonium excretion $p_{\text {crit }}$ was very similar when compared to the respiratory $p_{\text {crit }}$ in all species observed and ammonium excretion at anoxia was drastically down-regulated in E. mucronata. Mean $( \pm \mathrm{SD})$ standardized ammonium excretion at severe hypoxia $\left(p \mathrm{O}_{2}<0.5 \mathrm{kPa}\right.$ ) was significantly reduced by a factor of 5.9 compared to ammonium excretion $(0.65 \pm 0.33$ vs. 


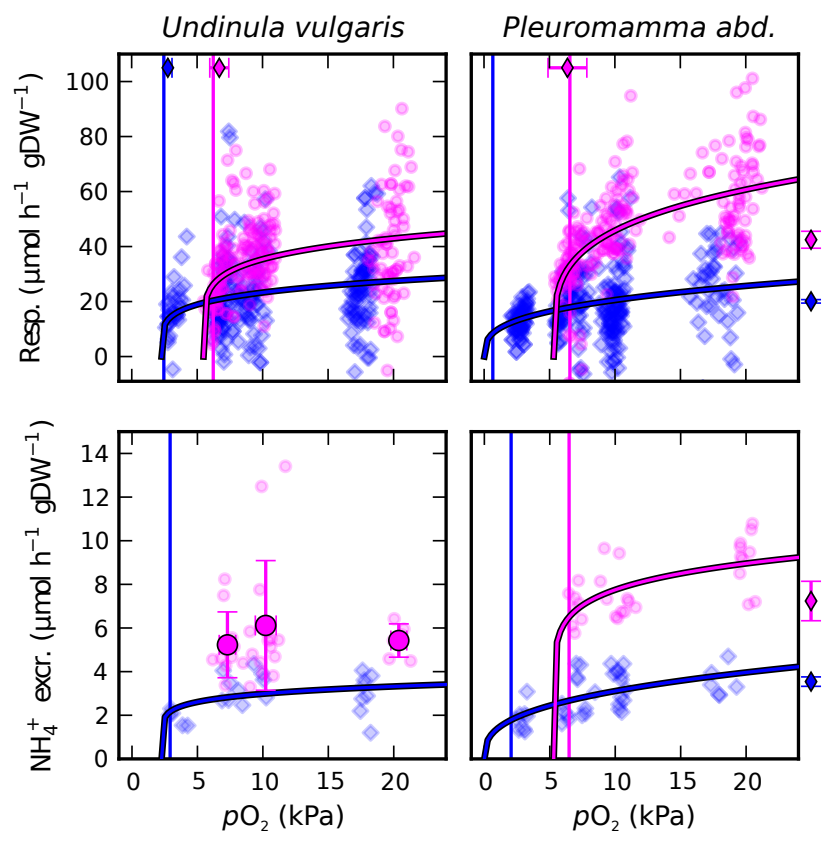

Figure 5. Weight-specific respiration and ammonium excretion rates of Undinula vulgaris and Pleuromamma abdominalis at different oxygen partial pressures and temperatures $\left(\mathrm{CO}_{2}\right.$-plus and $\mathrm{CO}_{2}$ minus treatments combined). Magenta symbols $=23^{\circ} \mathrm{C}$, Blue symbols $=11^{\circ} \mathrm{C}$. Transparent dots represent individual measurements. Solid curves indicate the power function fits to the data. Regression coefficients are given in Table 3. Solid vertical lines indicate the respective $p_{\text {crit }}$. Horizontal error bars in the upper panels indicate the mean $( \pm \mathrm{SD})$ lethal $p \mathrm{O}_{2}$ at the respective temperature. A power function could not be fitted to the ammonium excretion data for $U$. vulgaris at $23^{\circ} \mathrm{C}$, therefore the mean $( \pm \mathrm{SD})$ excretion rates for the three pre-set oxygen levels (100\% air saturation, 50 and $33 \%$ ) are plotted with vertical errorbars. Respiration and excretion rates were standardized to a mean dry mass of $0.1 \mathrm{~g}$. Error bars right beside the plots indicate the respiration or ammonium excretion rate ( \pm SE) calculated according to Ikeda (2014) for calanoid copepods $(0.1 \mathrm{gDW})$ at the respective temperature.

$\left.3.82 \pm 2.54 \mu \mathrm{mol} \mathrm{h}^{-1} \mathrm{gDW}^{-1}\right)$ under normoxia (15-22 $\mathrm{kPa}$ $p \mathrm{O}_{2}, t$ test, $p<0.01$ ) in E. mucronata.

Ammonium excretion rates calculated according to Ikeda (2014) for $0.1 \mathrm{~g}$ copepods or euphausiids coincided well with the excretion rates observed at normoxia in almost all species (Figs. 5, 6). Only the excretion rates observed in E. gibboides were lower than predicted. Stomachs of E. gibboides were mostly half-full and midgut colouration ranged between 1 and 2 in this species.

\section{Discussion}

Empirical models exist to predict copepod (Ikeda, 2014) and euphausiid (Tremblay et al., 2014; Ikeda, 2014) respiration and excretion rates, but these models do not include $p \mathrm{O}_{2}$ or ${ }_{p} \mathrm{CO}_{2}$ as environmental factors. We developed here an ap-

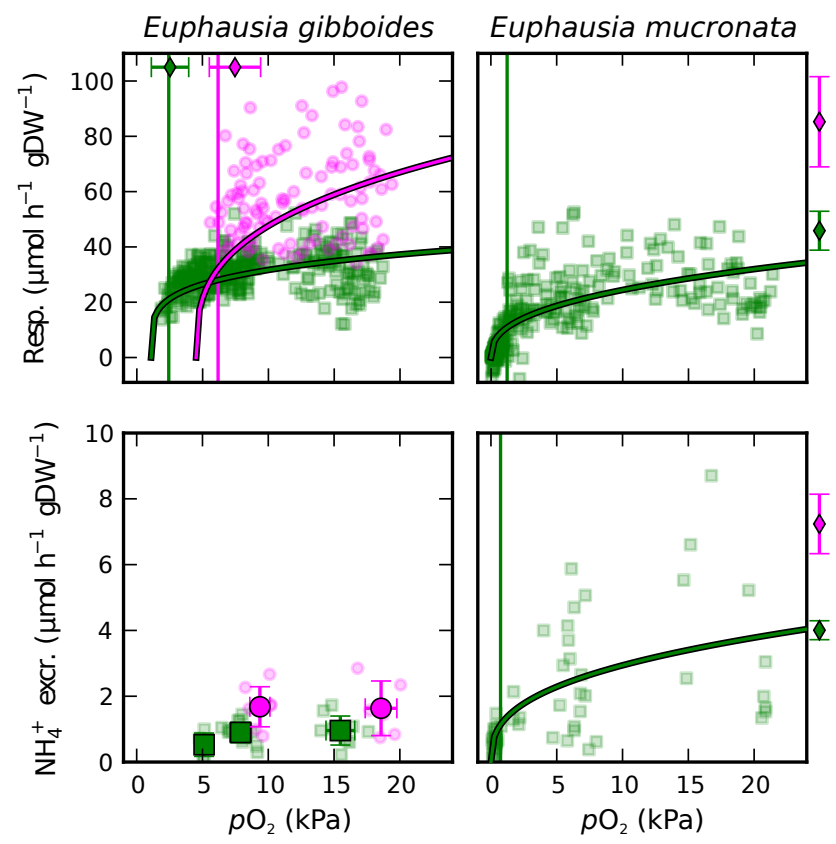

Figure 6. Weight-specific respiration and ammonium excretion rates of Euphausia gibboides and Euphausia mucronata at different oxygen partial pressures and temperatures $\left(\mathrm{CO}_{2}\right.$-plus and $\mathrm{CO}_{2-}$ minus treatments combined). Magenta symbols $=23^{\circ} \mathrm{C}$, Green symbols $=13^{\circ} \mathrm{C}$. Transparent dots represent single measurements. Solid curves indicate the power function fits to the data. Regression coefficients are given in Table 3. Solid vertical lines indicate the respective $p_{\text {crit }}$ for respiration and ammonium excretion. Horizontal error bars indicate the mean $( \pm \mathrm{SD})$ lethal $\mathrm{pO}_{2}$ at the given temperature for E. gibboides. A power function could not be fitted to the ammonium excretion data for E. gibboides, therefore the mean $( \pm \mathrm{SD})$ excretion rates for the three pre-set oxygen levels $(100 \%$ air saturation, 50 and $33 \%$ ) are plotted with vertical errorbars. Respiration and excretion rates were standardized to a mean dry mass of $0.1 \mathrm{~g}$. Error bars right beside the plots indicate the respiration or ammonium excretion rate $( \pm$ SE) calculated according to Ikeda (2014) for euphausiids $(0.1 \mathrm{gDW})$ at the respective temperature.

proach to determine copepod and euphausiid respiration and excretion rates at temperatures, and oxygen and carbon dioxide levels consistent with those found in the ETNA and ETSP OMZ. We furthermore tested whether respiration and excretion rates are altered when the oxygen, but not the carbon dioxide level is experimentally adjusted to represent $\mathrm{OMZ}$ conditions compared to the scenario when both levels are adjusted according to OMZ conditions.

\subsection{Impact of $p \mathrm{CO}_{2}$-levels on respiration and excretion}

As expected, the use of $\mathrm{CO}_{2}$-minus gas mixes resulted in a removal of $\mathrm{CO}_{2}$ from the incubation water, mirrored in a $\mathrm{pH}$ increase and a $p \mathrm{CO}_{2}$ decrease. The use of $\mathrm{CO}_{2}$-plus gas mixes allowed a more realistic simulation of OMZ conditions. $\mathrm{pH}, A_{\mathrm{T}}$ and $C_{\mathrm{T}}$ data were available for the Peruvian OMZ (WOCE, 2002) and we calculated the $\mathrm{CO}_{2}$-plus 
Table 2. Recommended volumetric composition for premixed gases for the ETSP OMZ.

\begin{tabular}{llrrr}
\hline & $50 \%$ air sat. & $33 \%$ air sat. & $10 \%$ air sat \\
\hline \multirow{2}{*}{ ETSP CO 2 -plus } & Nitrogen & 89.56 & 93.00 & 97.81 \\
& Oxygen & 10.36 & 6.91 & 2.07 \\
& Carbon dioxide & 0.08 & 0.09 & 0.11 \\
\hline
\end{tabular}

Table 3. Lethal $p \mathrm{O}_{2}$, parameter estimates $(a, b)$ of fitted power functions, $p_{\text {crit }}$ and $Q_{10}$ values for respiration and excretion rate data.

\begin{tabular}{|c|c|c|c|c|c|c|c|c|c|c|c|}
\hline Species & $\begin{array}{l}\text { Target } \\
\text { Temp. } \\
\left({ }^{\circ} \mathrm{C}\right)\end{array}$ & $\begin{array}{r}\text { mean lethal } \\
p \mathrm{O}_{2}(\mathrm{kPa}) \\
(\mathrm{SD}, n)\end{array}$ & $\begin{array}{r}\text { minimum } \\
\text { lethal } p \mathrm{O}_{2} \\
(\mathrm{kPa})\end{array}$ & $a_{\text {resp }}$ & $b_{\text {resp }}$ & $\begin{array}{r}p_{\text {crit, resp }} \\
(\mathrm{kPa})\end{array}$ & $a_{\mathrm{NH}_{4} \text {-excr }}$ & $b_{\mathrm{NH}_{4} \text {-excr }}$ & $\begin{array}{r}p_{\text {crit }} \mathrm{NH}_{4} \text {-excr } \\
(\mathrm{kPa})\end{array}$ & $Q_{10, \text { resp }}$ & $Q_{10, \mathrm{NH}_{4} \text {-excr }}$ \\
\hline U. vulgaris & 11 & $2.7(0.3,6)$ & 2.3 & 15.48 & 0.20 & 2.4 & 2.29 & 0.13 & 2.9 & 1.4 & 1.6 \\
\hline U. vulgaris & 23 & $6.6(0.7,6)$ & 5.5 & 27.55 & 0.17 & 6.2 & NA & NA & NA & & \\
\hline P.abdominalis & 11 & NA & NA & 9.62 & 0.33 & 0.6 & 1.51 & 0.30 & 1.8 & 2.0 & 2.3 \\
\hline P.abdominalis & 23 & $6.3(1.0,2)$ & 5.3 & 31.31 & 0.25 & 6.5 & 6.37 & 0.13 & 6.5 & & \\
\hline E. gibboides & 13 & $2.5(1.4,20)$ & 1.1 & 19.70 & 0.22 & 2.4 & NA & NA & NA & 2.0 & 2.3 \\
\hline E. gibboides & 23 & $7.5(1.9,20)$ & 4.5 & 27.12 & 0.33 & 6.2 & NA & NA & NA & & \\
\hline E. mucronata & 13 & NA & NA & 10.00 & 0.39 & 0.6 & 1.27 & 0.36 & 0.73 & NA & NA \\
\hline E. mисronata & 20 & NA & NA & NA & NA & 2 to $4^{*}$ & NA & NA & NA & NA & NA \\
\hline
\end{tabular}

* Approximate $p_{\text {crit }}$ deduced from Fig. 2 in Teal and Carey (1967). NA = not applicable.

gas mix composition based on the available $\mathrm{pH}$ and $C_{\mathrm{T}}$ data. $p \mathrm{CO}_{2}$ calculated from $A_{\mathrm{T}}$ and $C_{\mathrm{T}}$ is lower and more realistic, as these two parameters can be estimated more reliably. We therefore now suggest the use of the gas mixes listed in Table 2 to experimentally establish Peruvian $\mathrm{OMZ} p \mathrm{O}_{2}$ and $p \mathrm{CO}_{2}$ levels.

Realistic adjustment of the carbonate system did not result in consistent, statistically significant changes in the respiration or ammonium excretion rate in tropical Atlantic copepod or euphausiid species, or the Pacific Euphausia mucronata, compared to artificially lowered $p \mathrm{CO}_{2}$-levels. In some experiments (e.g. respiration rate of $U$. vulgaris at $11^{\circ} \mathrm{C}$ and $10 \%$ air saturation) the number of replicates was low, but also in cases where many replicates were available, as well as with the GLM no significant effects were found. The approximate detection level of our approach was a 1.2-fold difference in respiration and a 1.5-fold difference in ammonia excretion. We did not acclimatize the animals to the respective test conditions, as we aimed to mimic DVM changes in temperature, $p \mathrm{O}_{2}$ and $p \mathrm{CO}_{2}$ experienced by the animals when migrating from the OMZ to the surface layer and back. These migrations are conducted within 1 to $5 \mathrm{~h}$ (Fischer and Visbeck, 1993; Heywood, 1996) and the animals should therefore be able to cope with fast changes in environmental conditions. Previously, copepods were found to be relatively robust if it comes to acute changes in $p \mathrm{CO}_{2}$ (Isari et al., 2015; Thor and Dupont, 2015; Thor and Oliva, 2015). Food quality and quantity, life history (Thor and Dupont, 2015; Thor and Oliva, 2015) and other environmental constraints (e.g. temperature, $p \mathrm{O}_{2}$ ) seem to be more important than $p \mathrm{CO}_{2}$ in determining metabolic rates. Thor and Dupont (2015) for example found that respiration rates of Pseudocalanus acuspes copepods reared in the laboratory for two generations at elevated $\mathrm{CO}_{2}$-levels $(0.09 \mathrm{kPa})$ had 1.14 -fold higher respiration rates than copepods reared at $0.04 \mathrm{kPa} p \mathrm{CO}_{2}$. Respiration rates of copepods reared at $0.15 \mathrm{kPa}$ were significantly reduced by a factor of 0.84 compared to those of copepods reared at $0.04 \mathrm{kPa} p \mathrm{CO}_{2}$. However, if animals reared at $0.09 \mathrm{kPa}$ were tested at $0.04 \mathrm{kPa}$ or vice versa, no significant changes in respiration rates were found. The same holds true for tests of animals raised at 0.04 and $0.15 \mathrm{kPa}$. Isari et al. (2015) found no statistically significant differences in respiration rates in Acartia grani and Oithona davisae upon acute exposure to $0.12 \mathrm{kPa} p \mathrm{CO}_{2}$, compared to $0.04 \mathrm{kPa}$. Results are however difficult to assess as the number of replicates was low $(n=2)$, and mortality in the batch incubations seemingly was not zero. Thor and Oliva (2015) found both increases and decreases in respiration rates after exposure to elevated $p \mathrm{CO}_{2}$ for 10 days in a Skagerrak population of $P$. acuspes, but not in a Svalbard population. Food was a better predictor of respiration rate than $\mathrm{pH}$ in both populations. Until now, only one study assessed metabolic responses of Euphausiids to $p \mathrm{CO}_{2}$-level changes (Saba et al., 2012). A statistically significant 3-fold increase in DOC excretion in response to an elevated $p \mathrm{CO}_{2}$ (0.07 vs. $0.04 \mathrm{kPa} ; 24 \mathrm{~h}$ incubations) was found for E. superba, whereas ammonium, phosphate and urea excretion were not significantly impacted. The increase in DOC excretion might be related to an observed increased feeding activity at elevated $p \mathrm{CO}_{2}$, which currently remains unexplained (Saba et al., 2012).

The fact that Pleuromamma abdominalis, E. gibboides and E. mucronata are naturally exposed to daily vary- 
ing $p \mathrm{CO}_{2}$-levels when migrating into and out of the $\mathrm{OMZ}$ might also explain why no consistent changes in respiration or excretion rates under $\mathrm{CO}_{2}$-plus vs. $\mathrm{CO}_{2}$-minus conditions were found in these species. Migrating organisms that are regularly exposed to $p \mathrm{CO}_{2}$-changes may be less sensitive than those that live at stable conditions. Rosa and Seibel (2008) found that in the cephalopod (Dosidicus gigas) routine metabolism was not impacted by exposure to a $p \mathrm{CO}_{2}$ of $0.1 \mathrm{kPa}$ at low temperatures characteristic for the ETSP OMZ. Maas et al. (2012a) found no significant differences in respiration rates when pteropods migrating into the $\mathrm{OMZ}$ were exposed to $\mathrm{OMZ} \mathrm{CO}$-levels $(0.1 \mathrm{kPa})$ compared to surface $\mathrm{CO}_{2}$-levels $(0.04 \mathrm{kPa})$ at $20^{\circ} \mathrm{C}$. Acute $\mathrm{CO}_{2}$ effects on metabolic activity in copepods and other DVM organisms therefore seem to be small and might also be masked by the response to concomitant changes in $\mathrm{O}_{2}$-levels the animals experience when migrating into and out of the OMZ.

\subsection{Effects of temperature and oxygen on metabolic activity}

That temperature strongly affects metabolic activity is well established and our results are consistent with the general observation that zooplankton metabolic activity doubles with a $10^{\circ} \mathrm{C}$ increase in temperature within the thermal window of the species (Ikeda, 2014). The $Q_{10}$ of respiration and ammonium excretion was relatively close to 2 in Euphausia gibboides and Pleuromamma abdominalis. The $Q_{10}$ was below 2 in Undinula vulgaris, but this might be related to the fact that this surface dwelling species is seldom exposed to $11^{\circ} \mathrm{C}$ and the $Q_{10}$ therefore might not be representative for the normal thermal range of this species. An increase in temperature furthermore impaired hypoxia tolerance as indicated by a higher lethal $p \mathrm{O}_{2}$, respiration $p_{\text {crit }}$ and ammonium excretion $p_{\text {crit }}$ in all species tested. That elevated temperatures impair hypoxia tolerance has been found for numerous other marine species and quantitative estimates of the $p_{\text {crit }}$ can help to understand distribution patterns of marine organisms (e.g. Deutsch et al., 2015). Consistent with previous studies (e.g. Childress and Seibel, 1998), respiratory $p_{\text {crit }}$ values of E. mucronata from the ETSP were found to be lower than in species from weak- (E. gibboides, P. abdominalis and $U$. vulgaris) or non-OMZ regions (Childress and Seibel, 1998). No large differences in respiratory $p_{\text {crit }}$ could be observed when comparing the tropical Atlantic copepod and krill species. In general, our findings support the hypothesis that the critical oxygen partial pressure evolved to largely match the minimum oxygen level to which a species is regularly exposed (Seibel, 2011; Richards, 2011).

It seems reasonable to also transfer this concept to the impact of oxygen levels on ammonium excretion rates. A reduction of ammonium excretion under severely hypoxic or anoxic conditions was observed in E. mucronata and is consistent with similar observations from the squat lobster Pleuroncodes monodon (Kiko et al., 2015a) and from sev- eral calanoid copepods (Cass and Daily, 2014). It follows that both respiration and ammonium excretion are drastically reduced when crustacean zooplankton organisms are exposed to severe hypoxia or anoxia. The characterization of metabolic rates across the entire tolerated oxygen level spectrum (including, if possible, anoxia) is key to properly estimate effects of hypoxia and anoxia on species distribution and activity, as well as related biogeochemical fluxes. Furthermore, the determination of respiration and excretion rates over a wider temperature range and at higher resolution could be helpful to better understand differences in performance between migratory and non-migratory species. The inclusion of further factors (e.g. time of day and feeding status) could also lead to a more precise predictive model of zooplankton and nekton respiration and excretion rates.

\subsection{Implications for the calculation of biogeochemical fluxes of oxygen, carbon and nitrogen}

Several studies have assessed the active DVM-mediated fluxes and the passive particle-mediated fluxes of carbon and nitrogen in regions that mostly do not feature severe hypoxia $\left(p \mathrm{O}_{2}<1 \mathrm{kPa}\right.$ ) or anoxia at midwater depths (Longhurst et al., 1990; Zhang and Dam, 1997; Hidaka et al., 2001; Steinberg et al., 2002; Davison et al., 2013). Excretion rates used in these studies to calculate the active flux were obtained at mildly hypoxic $\left(p \mathrm{O}_{2}>1 \mathrm{kPa}\right)$ to normoxic conditions (e.g. Donnelly and Torres, 1988; Dagg et al., 1980; Steinberg et al., 2002). For OMZs demonstrating only mild hypoxia, such as the ETNA OMZ, this approach seems reasonable. The respiration and ammonium excretion $p_{\text {crit }}$ of Pleuromamma abdominalis were found to be 0.6 and $1.8 \mathrm{kPa}$ at $11^{\circ} \mathrm{C}$, respectively. The respiratory $p_{\text {crit }}$ of Euphausia gibboides was found to be $2.4 \mathrm{kPa}$ at $13{ }^{\circ} \mathrm{C}$ and no significant reduction of ammonium excretion was observed at a mean $p \mathrm{O}_{2}$ of $5.1 \mathrm{kPa}$ for $E$. gibboides at this temperature. P. abdominalis and $E$. gibboides normally do not encounter extremely low oxygen levels in their natural habitat. Oxygen concentrations in the ETNA seldom fall below $40 \mu \mathrm{mol} \mathrm{kg}-1\left(\sim 3.4 \mathrm{kPa}\right.$ at $12^{\circ} \mathrm{C}$, Karstensen et al., 2008). It follows that zooplankton respiration and excretion rates for biogeochemical flux calculations in the ETNA can be calculated from published empirical models of zooplankton respiration and excretion (Ikeda, 2014 ), if oxygen levels above $\sim 2.4 \mathrm{kPa}$ are encountered. However, food conditions should also be taken into account. Excretion rates of $E$. gibboides at normoxia were lower than predicted via the empirical model by Ikeda (2014), possibly due to low food availability as indicated by low midgut colouration scores.

Estimates of DVM-mediated fluxes to midwater depth with drastically reduced oxygen levels in the Pacific (e.g. Longhurst et al., 1990; Escribano et al., 2009; Bianchi et al., 2014) are likely too high. E. mucronata migrates to the core of the ETSP OMZ that features oxygen concentrations below $4 \mu \mathrm{mol} \mathrm{O} \mathrm{kg}^{-1}(\sim 0.34 \mathrm{kPa})$ (Antezana 2009). Later 
work by Thamdrup et al. (2012) showed that the core of the ETSP OMZ is often anoxic. Antezana (2002) tested the dependence of respiration on oxygen concentration at $13^{\circ} \mathrm{C}$, but only tested oxygen levels $>1.8 \mathrm{kPa}\left(21 \mu \mathrm{mol} \mathrm{O}_{2} \mathrm{~kg}^{-1}\right)$ and therefore did not characterize the response of $E$. $m u$ cronata to the ETSP OMZ core conditions. A reduction in respiration activity at oxygen levels of 1.8 to $3.5 \mathrm{kPa}$ (21 to $43 \mu \mathrm{mol} \mathrm{O} \mathrm{kg}^{-1}$ ) in comparison to measurements at normoxia was not observed (Antezana, 2002). We here show that reduction in respiration and ammonium excretion sets in at about $1 \mathrm{kPa}\left(\sim 12 \mu \mathrm{mol} \mathrm{O}_{2} \mathrm{~kg}^{-1}\right)$ in E. mucronata. Specimens migrating to the $\mathrm{OMZ}$ core therefore are exposed to oxygen concentrations below their $p_{\text {crit }}$ for respiration and ammonium excretion. We obtained similar results for the squat lobster Pleuroncodes monodon that also seems to conduct regular migrations to the OMZ core (Kiko et al., 2015a) and Cass and Daly (2014) report a strong reduction of nitrogen excretion in several copepod species at oxygen levels of 4 to $17 \mu \mathrm{mol} \mathrm{O} \mathrm{kg}^{-1}$ (0.3 to $\left.1.3 \mathrm{kPa}\right)$. It follows that calculations of DVM-mediated respiratory carbon dioxide and ammonium release into the anoxic core of the Pacific OMZ need to be adjusted. We observed here a 5.3-fold reduction of ammonium excretion in E. mucronata and found a 4-fold reduction in $P$. monodon (Kiko et al., 2015a). Generalizations that DVM mediated ammonium export is $20 \%$ of the passive export flux (Bianchi et al., 2014) seem invalid and it seems unlikely that DVM mediated ammonium supply to anoxic OMZs can support anammox to a large extent. Parameterizations that account for changes in respiration and ammonium excretion with decreasing oxygen levels should be applied in biogeochemical modelling studies to calculate DVM-mediated impacts on biogeochemical cycles in a consistent model framework.

OMZs are thought to expand due to climate change, as warming reduces the solubility of oxygen in seawater and enhances stratification (Stramma et al., 2008). During the last decades, it has been observed that the vertical extent and the area covered by tropical oceanic OMZs expanded in the Eastern North Pacific (Bograd et al., 2008) as well as in the Indian Ocean, the ETSP and the ETNA (Stramma et al., 2008). Modelling studies predict a further decrease in the global oxygen inventory (Bopp et al., 2013; Cocco et al., 2013). However, the detailed extension of OMZs seems to be difficult to model and Cocco et al. (2013) come to the conclusion that "projections of the evolution of low $\mathrm{O}_{2}$ regions will vary among models and be affected by large uncertainties". Median deviations of the water volumes with oxygen levels below 5 and $50 \mu$ mol oxygen $\mathrm{kg}^{-1}$ predicted for the year 1990 by the 17 models investigated (Cocco et al., 2013; Bopp et al., 2013) from the volumes observed in 1990 (Bianchi et al., 2012) are 6.7 (range: 1.0 to 21.1) and 1.9 (range: 1.1 to 4.8 ), respectively. To some extent problems to predict the observed OMZ extensions might be related to an unrealistic representation of oxygen-dependent processes, including the regionally varying dependency of DVM-mediated export processes on the physiological capacities of the migrating organisms to cope with low oxygen levels. We expect that a decrease in oxygen levels below approximately $2.4 \mathrm{kPa}$ $\left(\sim 30 \mu \mathrm{mol} \mathrm{O} \mathrm{kg}^{-1}\right.$, at 11 to $13^{\circ} \mathrm{C}$ ) in the ETNA will cause avoidance of these regions and will therefore result in a reduction of DVM mediated export. Expansion of the anoxic core of the ETSP should also result in a reduction of DVMmediated fluxes, not via exclusion of anoxia-tolerant migrators, but via repression of their metabolic activity. Both effects would weaken the biological pump and would therefore affect the oceanic $\mathrm{CO}_{2}$ uptake capacity, possibly enhancing global warming.

\section{Conclusions}

We here show that variations in the environmental $p \mathrm{CO}_{2}$ do not result in a perceptible change in the respiration or ammonium excretion rates of tropical calanoid copepods or euphausiids. Decreases in temperature and $p \mathrm{O}_{2}$ result in the expected reduction of respiration rates in these species. We show for the first time that also the ammonium excretion rates are reduced at low oxygen levels in calanoid copepods and euphausiids, which speaks in favour of an overall suppression of metabolism in these species at low oxygen levels. It is therefore necessary to consider the effects of temperature and $\mathrm{pO}_{2}$ on metabolic activity of zooplankton and nekton when calculating or modelling DVM-mediated fluxes in $\mathrm{OMZ}$ regions or on a global scale.

\section{Data availability}

Respiration and excretion data are available at https: //doi.pangaea.de/10.1594/PANGAEA.853919 (Kiko et al., 2015b).

Acknowledgements. We would like to thank captains and crews of RV Maria S Merian and RV Meteor, as well as the chief scientists of MSM22 (Peter Brandt), M93 (Gaute Lavik and Thorsten Kanzow) and M97 (Toste Tanhua) for their support during this study. This study was financed by the Deutsche Forschungsgemeinschaft via the Sonderforschungsbereich 754 "Climate-Biogeochemistry Interactions in the Tropical Ocean".

Edited by: M. Grégoire

\section{References}

Antezana, T.: Adaptive behavior of Euphausia mucronata in relation to the oxygen minimum layer of the Humboldt Current, in: Oceanography of the Eastern Pacific, edited by: Färber-Lorda, J., Vol II. Editorial CICESE, Ensenada, 29-40, 2002.

Antezana, T.: Species-specific patterns of diel migration into the Oxygen Minimum Zone by euphausiids in the Humboldt Current Ecosystem, Progr. Oceanogr., 83, 228-236, 2009. 
Antezana, T.: Euphausia mucronata: A keystone herbivore and prey of the Humboldt Current System, Deep-Sea Res. Pt. II, 57, 652662,2010

Auel, H. and Verheye, H. M.; Hypoxia tolerance in the copepod Calanoides carinatus and the effect of an intermediate oxygen minimum layer on copepod vertical distribution in the northern Benguela Current upwelling system and the Angola-Benguela Front, J. Exp. Mar. Biol. Ecol., 352, 234-243, 2007.

Bianchi, D., Dunne, J., Sarmiento, J., and Galbraith, E.: Data-based estimates of suboxia, denitrification and $\mathrm{N}_{2} \mathrm{O}$ production in the ocean, and their sensitivities to change, Global Biogeochem. Cy., 26, 6550-6555, 2012.

Bianchi, D., Babbin, A. R., and Galbraith, E. D.: Enhancement of anammox by the excretion of diel vertical migrators, P. Natl. Acad. Sci. USA, 111, 15653-15658, 2014.

Bograd, S. J., Castro, C. G., Di Lorenzo, E., Palacios, D. M., Bailey, H., Gilly, W., and Chavez, F. P.: Oxygen declines and the shoaling of the hypoxic boundary in the California Current, Geophys. Res. Lett., 35, L12607, doi:10.1029/2008GL034185, 2008.

Bopp, L., Resplandy, L., Orr, J. C., Doney, S. C., Dunne, J. P., Gehlen, M., Halloran, P., Heinze, C., Ilyina, T., Séférian, R., Tjiputra, J., and Vichi, M.: Multiple stressors of ocean ecosystems in the 21st century: projections with CMIP5 models, Biogeosciences, 10, 6225-6245, doi:10.5194/bg-10-6225-2013, 2013

Brandt, P., Bange, H. W., Banyte, D., Dengler, M., Didwischus, S.-H., Fischer, T., Greatbatch, R. J., Hahn, J., Kanzow, T., Karstensen, J., Körtzinger, A., Krahmann, G., Schmidtko, S., Stramma, L., Tanhua, T., and Visbeck, M.: On the role of circulation and mixing in the ventilation of oxygen minimum zones with a focus on the eastern tropical North Atlantic, Biogeosciences, 12, 489-512, doi:10.5194/bg-12-489-2015, 2015.

Cass, C. J. and Daly K. L.: Eucalanoid copepod metabolic rates in the oxygen minimum zone of the eastern tropical north Pacific: Effects of oxygen and temperature, Deep-Sea Res. Pt. I, 94, 137149, 2014.

Chahsavar-Archard, V. and Razouls, C.: Les copépodes pélagiques au sud-est des iles du Cap Vert, I. Aspects qualitatifs (Mission Guidôme du N.O. "J. Charcot", septembre-octobre 1976), Vie Milieu, 32, 25-45, 1982.

Childress, J. J.: The respiratory rates of midwater crustaceans as a function of depth of occurrence and relation to the oxygen minimum layer off Southern California, Comp. Biochem. Physiol., 50, 787-799, 1975.

Childress, J. J. and Seibel, B. A.: Life at stable low oxygen levels: Adaptations of animals to oceanic oxygen minimum layers, J. Exp. Biol., 201, 1223-1232, 1998.

Cocco, V., Joos, F., Steinacher, M., Frölicher, T. L., Bopp, L., Dunne, J., Gehlen, M., Heinze, C., Orr, J., Oschlies, A., Schneider, B., Segschneider, J., and Tjiputra, J.: Oxygen and indicators of stress for marine life in multi-model global warming projections, Biogeosciences, 10, 1849-1868, doi:10.5194/bg-10-18492013, 2013.

Deutsch, C., Ferrel, A., Seibel, B. A., Pörtner, H.-O., and Huey, R. B.: Climate change tightens a metabolic constraint on marine habitats, Science, 348, 1132-1135, 2015.

Dagg, M., Cowles, T., Whitledge, T., Smith, S., Howe, S., and Judkins, D.: Grazing and excretion by zooplankton in the Peru up- welling system during April 1977, Deep-Sea Res., 27, 43-59, 1980.

Davison, P., Checkley Jr., D. M., Koslow, J., and Barlow, J.: Carbon export mediated by mesopelagic fishes in the northeast Pacific Ocean, Prog. Oceanogr., 116, 14-30, 2013.

Donnelly, J. and Torres, J. J.: Oxygen consumption of midwater fishes and crustaceans from the eastern Gulf of Mexico, Mar. Biol., 97, 483-494, 1988.

Escribano, R., Hidalgo, P., and Krautz, C.: Zooplankton associated with the oxygen minimum zone system in the norther upwelling region of Chile during March 2000, Deep-Sea Res. Pt. II, 56, 1083-1094, 2009.

Ekau, W., Auel, H., Pörtner, H.-O., and Gilbert, D.: Impacts of hypoxia on the structure and processes in pelagic communities (zooplankton, macro-invertebrates and fish), Biogeosciences, 7, 1669-1699, doi:10.5194/bg-7-1669-2010, 2010.

Fischer, J. and Visbeck, M.: Seasonal variation of the daily zooplankton migration in the Greenland Sea, Deep-Sea Res. Pt. I, 40, 1547-1557, 1993.

Hagerman, L. and Szaniawska, A.: Haemolymph nitrogen compounds and ammonia efflux rates under anoxia in the brackish water isopod Saduria entomon, Mar. Ecol.-Prog. Ser., 103, 285289, 1994.

Hagerman, L., Søndergard, T., Weile, K., Hosie, D., and Uglow, R. F.: Aspects of blood physiology and ammonia excretion in Nephrops norvegicus under hypoxia, Comp. Biochem. Physiol., 97, 51-55, 1990.

Hauss, H., Franz, J. M. S., and Sommer, U.: Changes in N:P stoichiometry influence taxonomic composition and nutritional quality of phytoplankton in the Peruvian upwelling, J. Sea Res., 73, 74-85, 2012.

Heywood, K. J.: Diel vertical migration of zooplankton in the Northeast Atlantic, J. Plankton Res., 18, 163-184, 1996.

Hidaka, K., Kawaguchi, K., Murakami, M., and Takahashi, M.: Downward transport of organic carbon by diel migratory micronekton in the western equatorial Pacific: Its quantitative and qualitative importance, Deep-Sea Res. Pt. I, 48, 1923-1939, 2001.

Hofmann, A. F., Soetaert, K., Middelburg, J. J., and Meysman F. J. R.: AquaEnv: An aquatic acid-base modelling environment in $\mathrm{R}$, Aquat. Geochem., 16, 507-546, 2010.

Holmes, R. M., Aminot, A., Kérouel, R., Hooker, B. A., and Peterson, B. J.: A simple and precise method for measuring ammonium in marine and freshwater ecosystems, Can. J. Fish. Aquat Sci., 56, 1801-1808, 1999.

Ikeda, T.: Respiration and ammonia excretion by marine metazooplankton taxa: synthesis toward a global-bathymetric model, Mar. Biol., 161, 2753-2766, 2014.

Isari, S., Zervoudaki, S., Saiz, E., Pelejero, C., and Peters, J.: Copepod vital rates under $\mathrm{CO}_{2}$-induced acidification: a calanoid species and a cyclopoid species under short-term exposures, J. Plankton Res., 37, 912-922, doi:10.1093/plankt/fbv057, 2015.

Kalvelage, T., Jensen, M. M., Contreras, S., Revsbeck, N. P., Lam, P., Günter, M., LaRoche, J., Lavik, G., and Kuypers, M. M. M.: Oxygen sensitivity of anammox and coupled N-cycle processes in oxygen minimum zones, PLoS ONE, 6, e29299, doi:10.1371/journal.pone.0029299, 2011. 
Karstensen, J., Stramma, L., and Visbeck, M.: Oxygen minimum zones in the eastern tropical Atlantic and Pacific oceans, Prog. Oceanogr., 77, 331-350, 2008.

Karstensen, J., Fiedler, B., Schütte, F., Brandt, P., Körtzinger, A., Fischer, G., Zantopp, R., Hahn, J., Visbeck, M., and Wallace, D.: Open ocean dead zones in the tropical North Atlantic Ocean, Biogeosciences, 12, 2597-2605, doi:10.5194/bg-12-2597-2015, 2015.

Keeling, R. F., Körtzinger, A., and Gruber, N.: Ocean deoxygenation in a warming world, Ann. Rev. Mar. Sci., 2, 199-229, 2010.

Kiko, R., Hauss, H., Dengler, M., Sommer, S., and Melzner, F.: The squat lobster Pleuroncodes monodon tolerates anoxic "dead zone" conditions off Peru, Mar. Biol., 162, 1913-1921, doi:10.1007/s00227-015-2709-6, 2015a.

Kiko, R., Hauss, H., Buchholz, F., and Melzner, F.: Ammonium excretion and respiration rate of tropical copepods and euphausiids measured during METEOR cruise M93, M97 and Maria S. Merian cruise MSM22, PANGAE, available at: https://doi. pangaea.de/10.1594/PANGAEA.853919, 2015 b.

Kroeker, K. J., Kordas, R. L., Crim, R. N., and Singh, G. G.: Metaanalysis reveals negative yet variable effects of ocean acidification on marine organisms, Ecol. Lett., 13, 1419-1434, 2010.

Lampert, W.: The adaptive significance of diel vertical migration of zooplankton, Funct. Ecol., 3, 21-27, 1989

Longhurst, A. R., Bedo, A. W., Harrison, W. G., Head, E. J. H., and Sameoto, D. D.: Vertical flux of respiratory carbon by oceanic diel migrant biota, Deep-Sea Res. Pt. I, 37, 685-694, 1990.

Maas, A. E., Wishner, K. F., and Seibel, B. A.: The metabolic response of pteropods to acidification reflects natural $\mathrm{CO}_{2}$ exposure in oxygen minimum zones, Biogeosciences, 9, 747757, doi:10.5194/bg-9-747-2012, 2012a.

Maas, A. E., Wishner, K. F., and Seibel, B. A.: Metabolic suppression in thecosomatous pteropods as an effect of low temperature and hypoxia in the eastern tropical North Pacific, Mar. Biol., 159, 1955-1967, 2012b.

Marshall, D. J., Bode, M., and White, C. R.: Estimating physiological tolerances - a comparison of traditional approaches to nonlinear regression techniques, J. Exp. Biol., 216, 2176-2182, 2013

Melzner, F., Thomsen, J., Koeve, W., Oschlies, A., Gutowska, M., Bange, H. W., Hansen, H. P., and Körtzinger A.: Future ocean acidification will be amplified by hypoxia in coastal habitats, Mar. Biol., 160, 1875-1888, 2013.

Meyer, J., Löscher, C. R., Neulinger, S. C., Reichel, A. F., Loginova, A., Borchard, C., Schmitz, R. A., Hauss, H., Kiko, R., and Riebesell, U.: Changing nutrient stoichiometry affects phytoplankton production, DOP accumulation and dinitrogen fixation - a mesocosm experiment in the eastern tropical North Atlantic, Biogeosciences, 13, 781-794, doi:10.5194/bg-13-781-2016, 2016.

Moloney, C. L. and Field, J. G.: General allometric equations for rates of nutrient uptake, ingestion, and respiration in plankton organisms, Limnol. Oceanogr., 34, 1290-1299, 1989.

Morris, D. J., Ward, P., and Clarke, A.: Some aspects of feeding in the Antarctic krill, Euphausia superba, Polar Biol., 2, 21-26, 1983.

Paulmier, A., Ruiz-Pino, D., and Garçon, V.: $\mathrm{CO}_{2}$ maximum in the oxygen minimum zone (OMZ), Biogeosciences, 8, 239-252, doi:10.5194/bg-8-239-2011, 2011.
Pierrot, D., Lewis, E., and Wallace, D. W. R.: MS Excel Program Developed for $\mathrm{CO}_{2}$ System Calculations, ORNL/CDIAC-105a, Carbon Dioxide Information Analysis Center, Oak Ridge National Laboratory, US Department of Energy, Oak Ridge, Tennessee, 2006.

Prosser, C. L.: Oxygen: respiration and metabolism, in: Comparative animal physiology, edited by: Prosser, C. L. and Brown, F. A., Saunders, Philadelphia, 165-211, 1961.

Putzeys, S.: Carbon active fluxes in the Northeast Atlantic subtropical gyre, $\mathrm{PhD}$ Thesis, Univ. de Las Palmas de Gran Canaria, available at: http://hdl.handle.net/10553/11069 (last access: 9 July 2015), 2013.

Razouls, C., de Bovée, F., Kouwenberg, J., and Desreumaux, N.: Diversity and Geographic Distribution of Marine Planktonic Copepods, 2005-2015, available at: http://copepodes.obs-banyuls.fr/ en, last access: 4 August 2015.

Richards, J. G.: Physiological, behavioral and biochemical adaptations of intertidal fishes to hypoxia, J. Exp. Biol., 214, 191-199, 2011.

Rosa, R. and Seibel, B. A.: Synergistic effects of climate-related variables suggest future physiological impairment in a top oceanic predator, Proc. Nat. Acad. Sci. USA, 105, 20776-20780, 2008.

Rosas, C., Martinez, E., Gaxiola, G., Brito, R., Sánchez, A., and Soto, L. A.: The effect of dissolved oxygen and salinity on oxygen consumption, ammonia excretion and osmotic pressure of Penaeus setiferus (Linnaeus) juveniles, J. Exp. Mar. Biol. Ecol., 234, 41-57, 1999.

Saba, G. K., Schofield, O., Torres, J. J., Ombres, E. H., and Steinberg, D. K.: Increased feeding and nutrient excretion of adult Antarctic krill, Euphausia superba, exposed to enhanced carbon dioxide $\left(\mathrm{CO}_{2}\right)$, Plos One, 7, e52224, doi:10.1371/journal.pone.0052224, 2012.

Seibel, B. A.: Critical oxygen levels and metabolic suppression in oceanic oxygen minimum zones, J. Exp. Biol., 214, 326-336, 2011.

Semenova, T. N., Timonin, A. G., and Flint, M. V.: Characteristic features of the lateral and vertical distributions of abundant zooplankton species near the Peruvian coast, Oceanology, 22, 216220, 1982.

Siegel, V.: Euphausia gibboides Ortmann, 1893, in: World Euphausiacea database, 2015, edited by: Siegel, V., World Register of Marine Species at http://www.marinespecies.org/aphia.php?p= taxdetails\&id=110684, last access: 9 July 2015.

Steinberg, D. K., Carlson, C. A., Bates, N. R., Goldthwait, S. A., Madin, L. P., and Michaels, A. F.: Zooplankton vertical migration and the active transport of dissolved organic and inorganic carbon in the Sargasso Sea, Deep-Sea Res. Pt. I, 47, 137-158, 2000.

Steinberg, D. K., Goldthwait, S. A., and Hansell, D. A.: Zooplankton vertical migration and the active transport of dissolved organic and inorganic nitrogen in the Sargasso Sea, Deep-Sea Res. Pt. I, 49, 1445-1461, 2002.

Stramma, L., Johnson, G. C., Sprintall, J., and Mohrholz, V.: Expanding Oxygen-Minimum Zones in the Tropical Oceans, Science, 320, 655-658, 2008.

Stramma, L., Prince, E. D., Schmidtko, S., Luo, J., Hoolihan, J. P., Visbeck, M., Wallace, D. W. R., Brandt, P., and Körtzinger, A.: Expansion of oxygen minimum zones may reduce available habi- 
tat for tropical pelagic fishes, Nature Climate Change, 2, 33-37, 2012.

Svetlichny, L., Hubareva, E., and Arashkevich, E.: Physiological and behavioural response to hypoxia in active and diapausing stage V copepodites of Calanus euxinus, Arch. Hydrobiol. Spec. Issues Adv. Limnol., 52, 507-519, 1998.

Teal, J. M. and Carey, F. G.: Respiration of a Euphausiid from the Oxygen Minimum Layer, Limnol. Oceanogr., 12, 548-550, 1967.

Thamdrup, B., Dalsgaard, T., and Revsbech, N. P.: Widespread functional anoxia in the oxygen minimum zone of the Eastern South Pacific, Deep-Sea Res. Pt. I, 65, 36-45, 2012.

Thomsen, J. and Melzner, F.: Moderate seawater acidification does not elicit long-term metabolic depression in the blue mussel Mytilus edulis, Mar. Biol., 157, 2667-2676, 2010.

Thor, P. and Dupont, S.: Transgenerational effects alleviate severe fecundity loss during ocean acidification in a ubiquitous planktonic copepod, Glob. Change Biol., 21, 2261-2271, 2015.

Thor, P. and Oliva, E. O.: Ocean acidification elicits different energetic responses in an Arctic and a boreal population of the copepod Pseudocalanus acuspes, Mar. Biol., 162, 799-807, 2015.

Tremblay, N., Werner, T., Huenerlage, K., Buchholz, F., Abele, D., Meyer, B., and Brey, T.: Euphausiid respiration model revamped: Latitudinal and seasonal shaping effects on krill respiration rates, Ecol. Modell., 291, 233-241, 2014.
Trübenbach, K., Pegado, M. R., Seibel, B. A., and Rosa, R.: Ventilation rates and acivity levels of juvenile jumbo squid under metabolic suppression in the oxygen minimum zone, J. Exp. Biol., 216, 359-368, 2013.

Wishner, K. F., Gowing, M. M., and Gelfman, C.: Mesozooplankton biomass in the upper $1000 \mathrm{~m}$ in the Arabian Sea: overall seasonal and geographic patterns, and relationship to oxygen gradients, Deep-Sea Res. Pt. II, 45, 2405-2432, 1998.

WOCE Data Products Committee: WOCE Global Data, Version 3.0, WOCE International Project Office, WOCE Report No. 180/02, Southampton, UK, November 2002.

Zhang, X. S. and Dam, H. G.: Downward export of carbon by diel migrant mesozooplankton in the central equatorial Pacific, DeepSea Res. Pt. II, 44, 2191-2202, 1997. 